\title{
White coat ceremonies for new medical students
}

Raanan Gillon Imperial College School of Medicine, University of London

Earlier this year I attended my first white coat ceremony for incoming medical students. So impressed was I by the event that I feel impelledalmost duty bound-to spread the word, for few outside the USA are likely to have heard of these ceremonies.

Essentially they are a rite of passage, welcoming the new medical student into the medical profession, albeit as a student member. They occur right at the beginning of the medical course before the students have taken any lectures or laboratory classes, and the students' families and friends are invited by the medical school to attend. The students are congratulated on their achievement in being selected as medical students, and told about the commitment that, as student doctors, they are making both to becoming and staying proficient in the science and technique of medicine and also to the human obligations of being a doctor-especially to the central obligation of caring for their patients. (The brochure at the ceremony I attended quoted from an eminent American physician of the 1930s, William Peabody: "The secret of caring for the patient ........ is caring for the patient"! - not a bad message on its own for the new medical student to take away). A physician with some special interest and/or skill in medical humanities then gives a lecture, welcoming the new students and emphasising the importance of the human side of medicine and the importance of integrating this into the science and technology of medical practice.

In the ceremony I attended, after all, including the medical faculty, had taken their seats in the auditorium everyone stood as the new students were led in procession to take their seats. A doctor who had graduated from that medical school then talked about his experiences at the school and subsequent career. The visiting speaker, a physician with a special interest in medical ethics, then gave a half-hour talk in which he linked the goals of medicine with the ethics of medicine, asking his audience never to forget to reflect on what the purposes of being a good doctor were. He urged them to be proud of the fact that the core objective of doctors was to do good for the health of the people they served. He recalled somewhat scathingly that in his student days there had been a tendency to pour scorn on the objective of serving humanity as a good reason for wishing to become a doctor, with corresponding advice to aspiring medical students never to say such things at interviews for medical school places and he welcomed the contemporary tendency to return to an explicit affirmation of this Hippocratic commitment. He explored the relationship of trying to do good and the ancient obligation of "primum non nocere", contemporary concerns both for respect for people's autonomy ("apart from other considerations, it's far easier to do good for people if you know and honour their values and aspirations") and justice ("the need to meet competing claims fairly-including claims on you"). The speaker wished not to be identified in this editorial but was happy for a brief gist of his remarks to be reported. In a subsequent session the students enthusiastically took the opportunity to question him and occasionally - as urged - to argue with him about a wide range of ethical issues that already interested and or concerned them in relation to the practice of medicine.

After the white coat lecture came the "robing ceremony". All 250 or so new medical students had been presented with a short white coat by the medical school and, as each student's name was called by a senior member of the faculty, several others including the dean of medicine, and the white coat lecturer, helped each student into his or her new coat-murmuring words of congratulations and good luck as they did so-sometimes vigorously assisted by cheering from the particular student's family and fans. Then came very short addresses from the dean and another senior doctor, after which the students stood and, led by one of the school's senior staff, read an affirmation of "professional commitment". They promised to 
pursue diligently their medical education and training from that day until they retired from medical practice; to put the interests of their patients before their own; to respect and value their fellow health professionals; to be tolerant, compassionate and honest; to respect, support and encourage their classmates, now their colleagues; to adhere to the university's student honour code, and to behave well and honourably throughout their medical careers, always striving to be worthy of the privilege of being a doctor and never abusing it. All then processed out to a sumptuous reception given by the medical school for the new students and their families and friends. When, as an outside observer, I discreetly asked some of the students afterwards what they thought of the ceremony- "what you really thought of it please!"-the small but random sample whom I asked had all been deeply impressed and pleased by it and were unanimous in their praise for it.

The first white coat ceremony seems to have been in 1993 in New York's College of Physicians and Surgeons. It was supported by a grant from a foundation established by a paediatrician and neurologist, Dr Arnold Gold, which was "dedicated to fostering humanism in medicine". The Arnold P Gold Foundation * identifies six essential components of the white coat ceremony, each designed to "help create an environment which fosters establishing a psychological contract for professionalism and empathy in medicine. First is the invitation to family and friends of the new student to attend, 'representing the support and value system closest to the student'. Second is the welcome at the ceremony by deans and other senior members of medical school and hospital, 'representing the value system of the school and the new profession they are about to enter'. Third is 'an inspiring address' by a physician role-model. Fourth is the personal 'cloaking' with the white coat - part of a 'bonding process' in which senior doctors demonstrate their belief in the student's ability to carry on the noble tradition of doctoring - 'a gift of faith and confidence personally delivered'. Fifth is the swearing of the Hippocratic Oath or other similar oath before the student's 'peers, family, friends and mentors'-a public acknowledgement by the students in front of 'very significant witnesses' of their willingness to assume the obligations and responsibilities of the medical profession. The sixth component is the reception celebrating the students' new professional status, following their rite of passage'There is nothing like food and a party atmosphere to reinforce an important and memorable moment'."

These six components, the foundation believes, alert new medical students to the need to balance excellence in science with compassionate patient care, and help them to identify important characteristics of "the complete doctor". Among these are a welcoming, nurturing and empathic demeanour (represented by the nature and atmosphere of the white coat ceremony); a caring for patients (the point of emphasis of the ceremony), and the commitment to such a balance between scientific excellence and compassionate care for patients affirmed by the presence at the ceremony of members of the medical faculty, doctors from related hospitals, and other "dignitaries and mentors".

The foundation asserts that feedback from both students and parents has been highly positive, and that "leading medical educators have hailed the 'white coat ceremony' as an important new concept for introducing students to medical school".

I have to say that starting from a position of indifferent scepticism I have changed into an enthusiastic supporter of the white coat ceremony. Medical professional life does indeed start at the beginning of medical studies, not at qualification - medical students are bound by at least some of the same professional commitments that bind all doctors (a few examples are the commitments to medical confidentiality, to working for the good of patients and to avoid harming them, and not to exploit their quasi-professional privileges, for example by taking sexual advantage of patients). Explicitly enrolling students into the profession welcomes them, affirms their new status and emphasises - at a highly impressionable stage of their careers - the importance of committing themselves to excellence, not only in the scientific and technical areas of medicine but also in its human and humanitarian aspects. Medical school deans and their colleagues throughout the world are warmly recommended to consider the possibility of introducing a white coat ceremony at their own school!

*The Arnold P Gold Foundation is at 260 Lincoln Street, Englewood, New fersey 07631, USA. 